\title{
Overexpression of Activation-Induced Cytidine Deaminase in MTX- and Age-Related Epstein-Barr Virus-Associated B-Cell Lymphoproliferative Disorders of the Head and Neck
}

\author{
Kentaro Kikuchi, ${ }^{1}$ Toshiyuki Ishige, ${ }^{2}$ Fumio Ide, ${ }^{1}$ Yumi Ito, ${ }^{3}$ \\ Ichiro Saito, ${ }^{4}$ Miyako Hoshino, ${ }^{5}$ Harumi Inoue, ${ }^{1}$ Yuji Miyazaki, ${ }^{1}$ \\ Tadashige Nozaki, ${ }^{6}$ Masaru Kojima, ${ }^{7}$ and Kaoru Kusama ${ }^{1}$ \\ ${ }^{1}$ Division of Pathology, Department of Diagnostic and Therapeutic Sciences, Meikai University School of Dentistry, \\ 1-1 Keyakidai, Sakado, Saitama 350-0283, Japan \\ ${ }^{2}$ Department of Pathology, Nihon University School of Medicine, 30-1 Oyaguchi-Kamimachi, Itabashi-ku, Tokyo 173-8610, Japan \\ ${ }^{3}$ Division of Diagnostic Pathology, Tsurumi University Dental Hospital, 2-1-3 Tsurumi, Tsurumi-ku, Yokohama 230-8501, Japan \\ ${ }^{4}$ Department of Pathology, Tsurumi University School of Dental Medicine, 2-1-3 Tsurumi, Tsurumi-ku, Yokohama 230-8501, Japan \\ ${ }^{5}$ Second Division of Oral and Maxillofacial Surgery, Department of Diagnostic and Therapeutic Sciences, \\ Meikai University School of Dentistry, 1-1 Keyakidai, Sakado, Saitama 350-0283, Japan \\ ${ }^{6}$ Department of Pharmacology, Osaka Dental University, 8-1 Kuzuhahanazono-cho, Hirakata, Osaka 573-1211, Japan \\ ${ }^{7}$ Department of Anatomic and Diagnostic Pathology, Dokkyo Medical University School of Medicine, 880 Oaza-kitakobayashi, \\ Mibu-machi, Shimotsuga-gun, Tochigi 321-0293, Japan
}

Correspondence should be addressed to Kentaro Kikuchi; k-kikuchi@dent.meikai.ac.jp

Received 7 November 2014; Revised 10 February 2015; Accepted 10 February 2015

Academic Editor: James L. Mulshine

Copyright (C) 2015 Kentaro Kikuchi et al. This is an open access article distributed under the Creative Commons Attribution License, which permits unrestricted use, distribution, and reproduction in any medium, provided the original work is properly cited.

\begin{abstract}
Recent research has shown that activation-induced cytidine deaminase (AID) triggers somatic hypermutation and recombination, in turn contributing to lymphomagenesis. Such aberrant AID expression is seen in B-cell leukemia/lymphomas, including Burkitt lymphoma which is associated with $c$-myc translocation. Moreover, Epstein-Barr virus (EBV) latent membrane protein-1 (LMP1) increases genomic instability through early growth transcription response-1 (Egr-1) mediated upregulation of AID in B-cell lymphoma. However, few clinicopathological studies have focused on AID expression in lymphoproliferative disorders (LPDs). Therefore, we conducted an immunohistochemical study to investigate the relationship between AID and LMP-1 expression in LPDs (MTX-/Age-related EBV-associated), including diffuse large B-cell lymphomas (DLBCLs). More intense AID expression was detected in LPDs (89.5\%) than in DLBCLs (20.0\%), and the expression of LMP-1 and EBER was more intense in LPDs (68.4\% and 94.7\%) than in DLBCLs (10.0\% and 20.0\%). Furthermore, stronger Egr-1 expression was found in MTX/Age-EBV-LPDs (83.3\%) than in DLBCLs (30.0\%). AID expression was significantly constitutively overexpressed in LPDs as compared with DLBCLs. These results suggest that increased AID expression in LPDs may be one of the processes involved in lymphomagenesis, thereby further increasing the survival of genetically destabilized B-cells. AID expression may be a useful indicator for differentiation between LPDs and DLBCLs.
\end{abstract}

\section{Introduction}

Epstein-Barr virus (EBV) is associated with a variety of lymphoproliferative disorders (LPDs) and other malignancies [15], including nasopharyngeal carcinoma, Hodgkin disease, and Burkitt lymphoma [6-9]. EBV-driven B-cell LPDs can be age-related or can occur in patients who are immunosuppressed due to primary immune deficiency, HIV infection, organ transplantation, and treatment with methotrexate or tumor necrosis factor- $\alpha$ antagonist for rheumatoid arthritis 


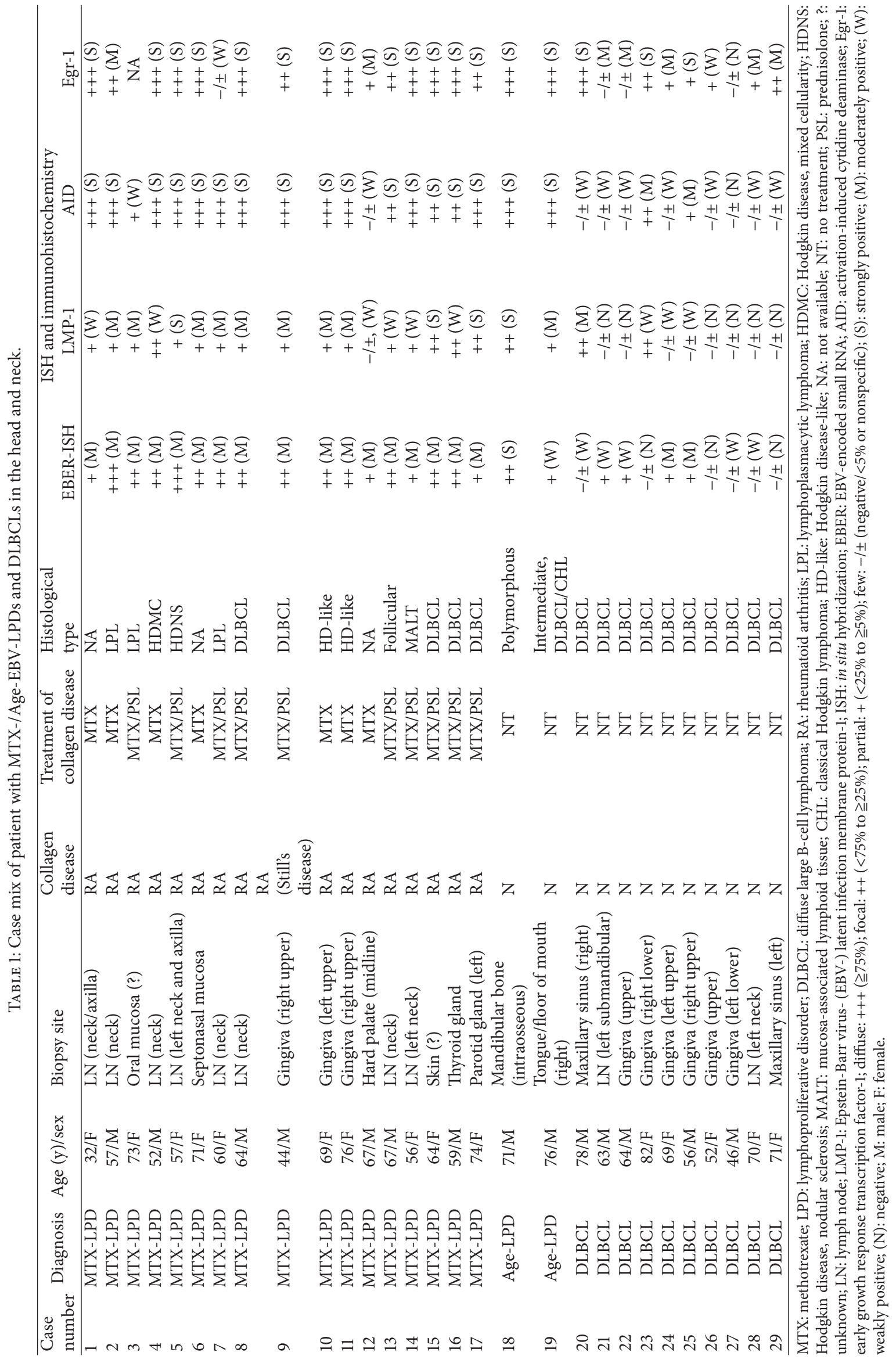


TABLE 2: Antibodies and dilutions used in this study.

\begin{tabular}{|c|c|c|c|c|c|}
\hline Antigen & Clone & Dilution & Pretreatment & $\begin{array}{l}\text { Primary antibody } \\
\text { incubation time }\end{array}$ & Source \\
\hline AID & - & 1:50 (rabbit polyclonal) & MW & $\begin{array}{c}\text { Overnight (about } 15 \mathrm{~h} \text {, } \\
\left.4^{\circ} \mathrm{C}\right)\end{array}$ & Serotec \\
\hline LMP-1 & CS. 1-4 & $\begin{array}{l}1: 100 \text { (mouse } \\
\text { monoclonal) }\end{array}$ & - & $\begin{array}{l}\text { Overnight (about } 15 \mathrm{~h} \text {, } \\
\left.\qquad 4^{\circ} \mathrm{C}\right)\end{array}$ & Dako \\
\hline Egr-1 & - & $1: 100$ (rabbit polyclonal) & - & Nonovernight (1 h, RT) & Rockland \\
\hline
\end{tabular}

AID: activation-induced cytidine deaminase; LMP-1: latent membrane protein-1; Egr-1: early growth response-1; MW: microwave oven (for 1 min at high voltage and then for $10 \mathrm{~min}$ at low voltage); - : none; RT: room temperature.

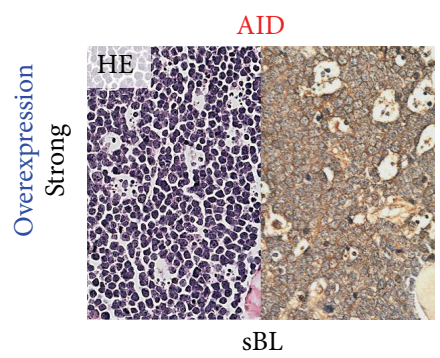

(a)

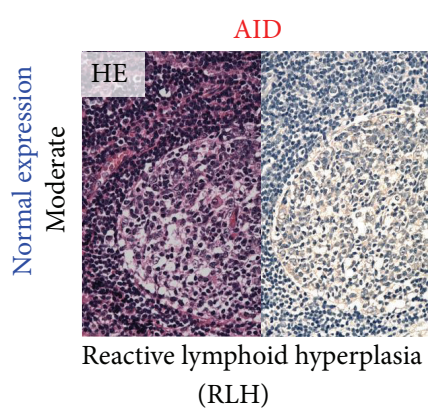

(e)

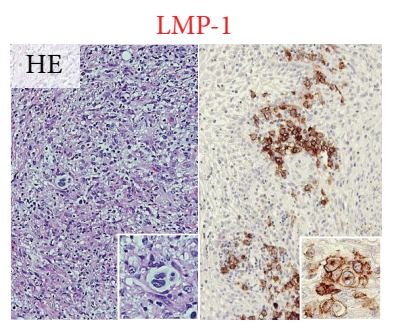

MTX-LPD

(b)

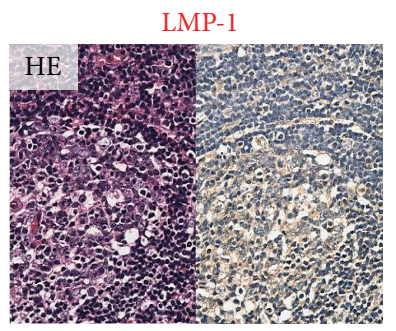

Reactive lymphoid hyperplasia (RLH)

(f)

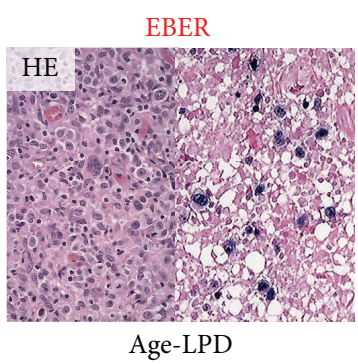

(c)

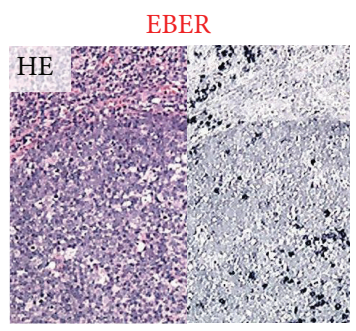

Reactive lymphoid hyperplasia (RLH)

(g)

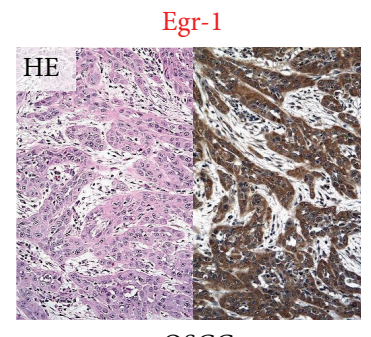

OSCC

(d)

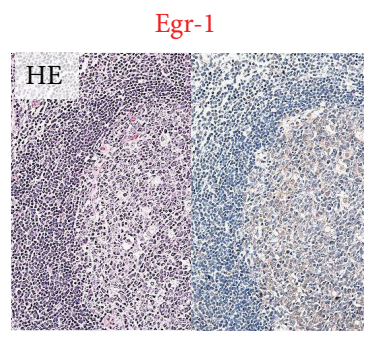

Reactive lymphoid hyperplasia

(RLH)

(h)

FIGURE 1: Positive control for AID, LMP-1, EBER, and Egr-1 in the overexpression and normal expression. (a) Sporadic Burkitt lymphoma (sBL) [34], (b) MTX-LPD [35], (c) Age-LPD [36], and (d) oral squamous cell carcinoma (OSCC) were used as an aberrant positive control (strong intensity/overexpression) for AID, LMP-1, EBER, and Egr-1 (hematoxylin-eosin staining: HE, left panel; immunohistochemical staining: IHC, right panel) $((\mathrm{a})-(\mathrm{d})$ original magnification $\times 100)$. Reactive lymphoid hyperplasia $(\mathrm{RLH})$ was used as normally positive control (moderate/normal expression) for (e) AID, (f) LMP-1, (g) EBER, and (h) Egr-1 ((e)-(h) original magnification $\times 100)$. (g) Germinal center B-cells were moderate/normal positive for EBER, and plasma cells were strongly positive for EBER (right panel).

$[10,11]$. The major EBV oncogene, latent membrane protein-1 (LMP-1), activates signaling pathways such as those involving nuclear factor-kappa-light-chain-enhancer of activated Bcells (NF- $\kappa \mathrm{B}$ ), which enhances B-cell survival and is essential for EBV-induced transformation [12-16]. LMP-1 is a $63 \mathrm{kDa}$ integral membrane protein with three domains and contains two distinct functional regions within its C-terminus, designated C-terminal activating regions 1 and 2 (CTAR1 and CTAR2). The protein also protects cancer cells from apoptosis, by inducing antiapoptotic proteins, including BCL-2, MCL-1, A20, early growth response transcription factor-1 (Egr-1), and SNARK [17-19]. Recent studies have shown that EBV-infected cells undergo hypermutation or switching of recombination in vivo via upregulation of activation-induced cytidine deaminase (AID) [20] and also that EBV-induced
AID is associated with oncogene mutations, which contribute to lymphomagenesis [21]. The relationship between LMP1 and cancer has been relatively well established, while the molecular mechanisms underlying AID induction remain to be fully clarified.

AID is normally expressed in germinal center (GC) Bcells [22], where it plays a central role in both somatic hypermutation and class switch recombination in humans and mice $[23,24]$. AID converts single-stranded genomic cytidine into uracil, with pronounced activity in the immunoglobulin variable and switch regions [25-28]. Aberrant expression of AID and abnormal targeting of AID activation in both Band non-B-cells cause DNA double-strand breaks (DSBs) and DNA point mutations in both Ig and non-Ig genes, inducing tumorigenesis [29]. AID is required for chromosomal DSBs 


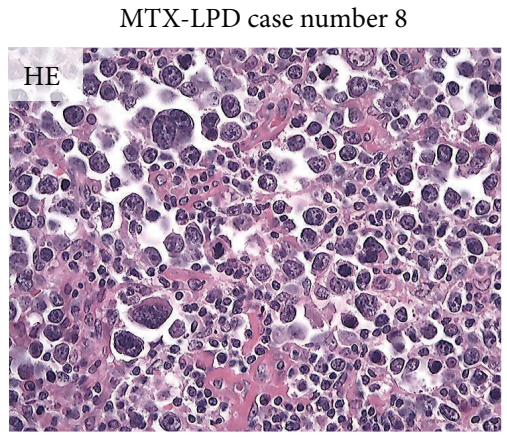

(a)

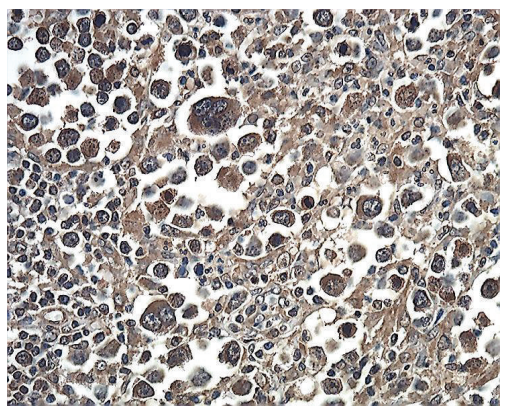

(d)
Age-LPD case number 19

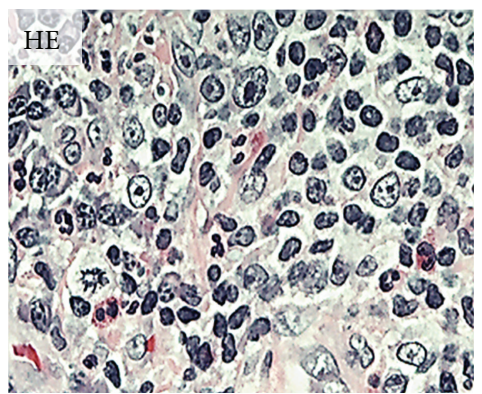

(b)

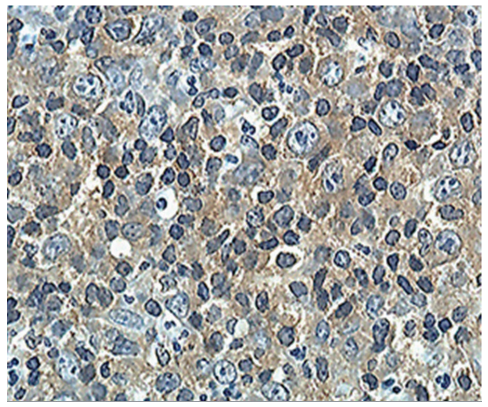

(e)
DLBCL case number 21

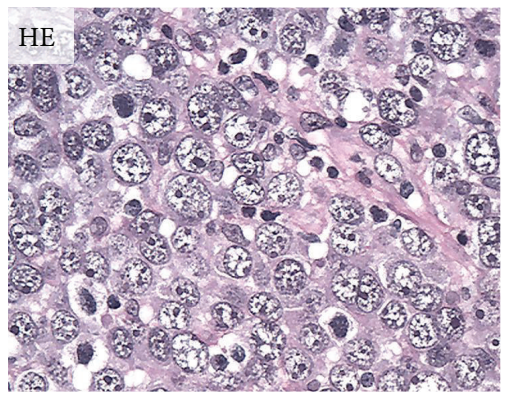

(c)

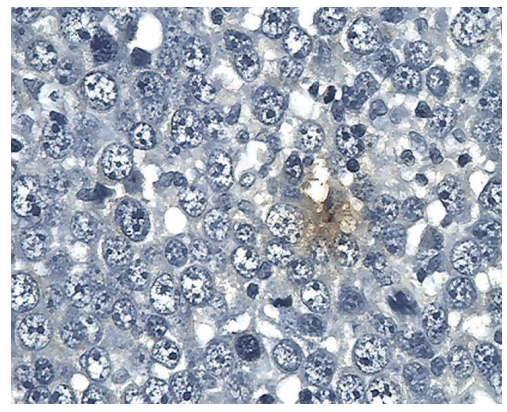

(f)

FIgURE 2: Distribution and intensity of AID expression in MTX-/Age-EBV-LPDs and DLBCLs in biopsy specimens. ((a)-(c)) HE stain and ((d)-(f)) AID by IHC (brownish color). AID positive atypical lymphoid cells were diffuse in (d) MTX-LPD and (e) Age-LPD but were few in (f) DLBCL. AID positive cells were of strong intensity in (d) MTX-LPD and (e) Age-LPD and were of (f) weak or moderate intensity in $\operatorname{DLBCL}((\mathrm{a})-(\mathrm{f})$ original magnification, $\times 200)$.

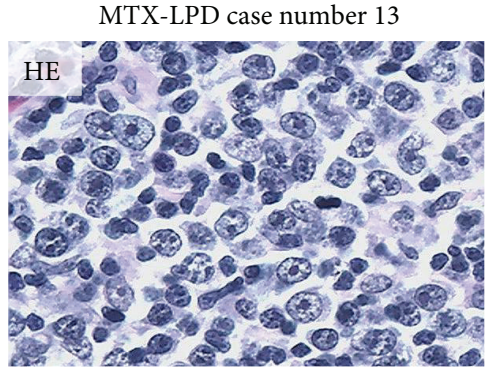

(a)

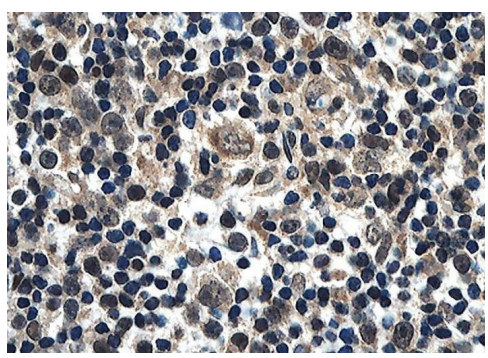

(d)

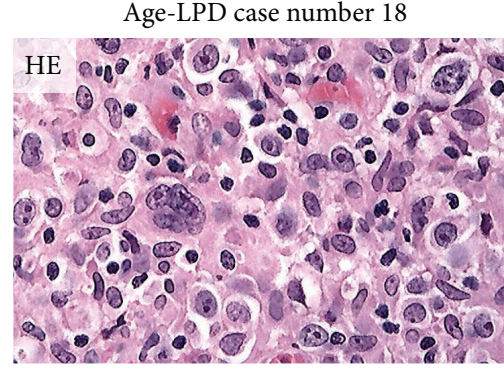

(b)

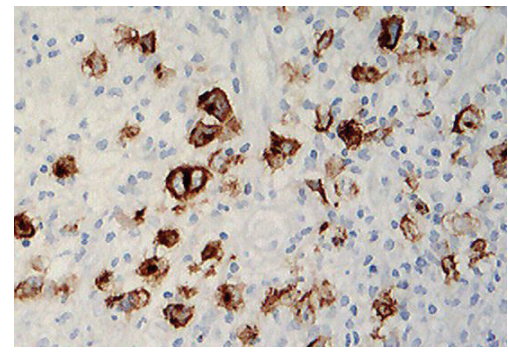

(e)
DLBCL case number 24

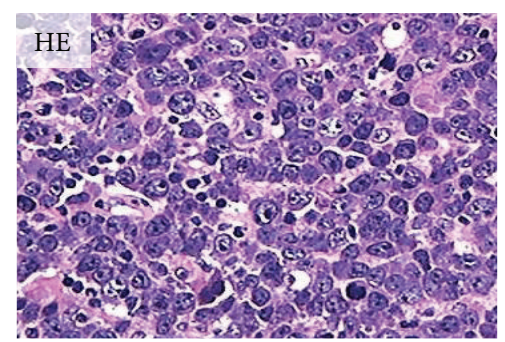

(c)

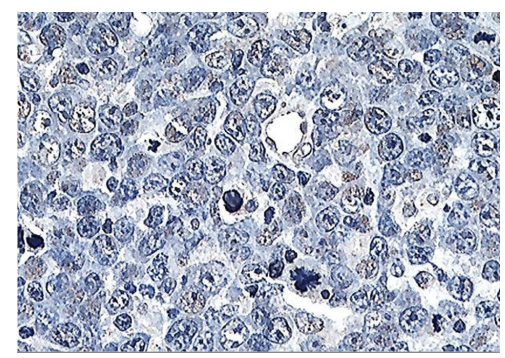

(f)

FIGURE 3: Distribution and intensity of LMP-1 expression in MTX-/Age-EBV-LPDs and DLBCLs in biopsy specimens. ((a)-(c)) HE stain and ((d)-(f)) LMP-1 by IHC. LMP-1 positive atypical lymphoid cells (brownish color) were diffuse or sporadic diffuse in (d) MTX-LPD or (e) Age-LPD but were not verifiable in (f) DLBCL. LMP-1 positive cells were of moderate or strong intensity in (d) MTX-LPD and (e) Age-LPD and were of weak or nonspecific intensity in (f) DLBCL ((a)-(f) original magnification, $\times 200)$. 


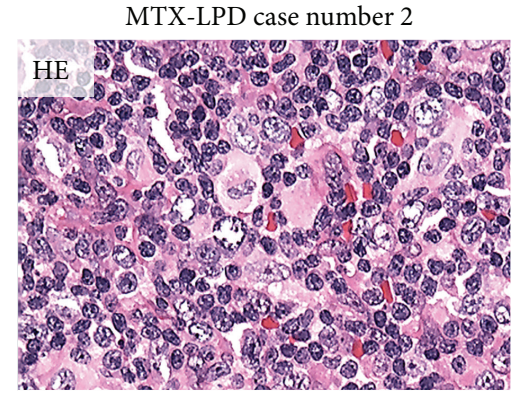

(a)

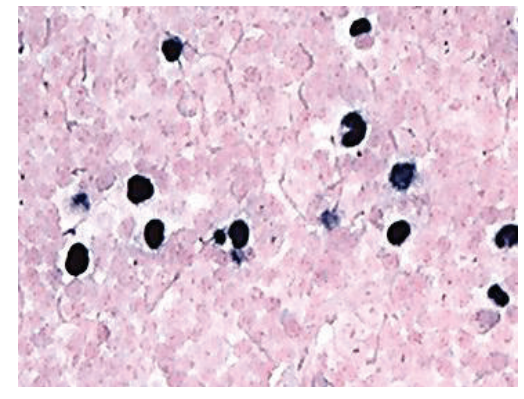

(d)

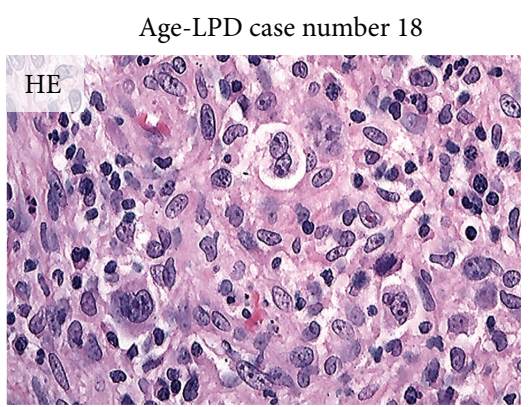

(b)

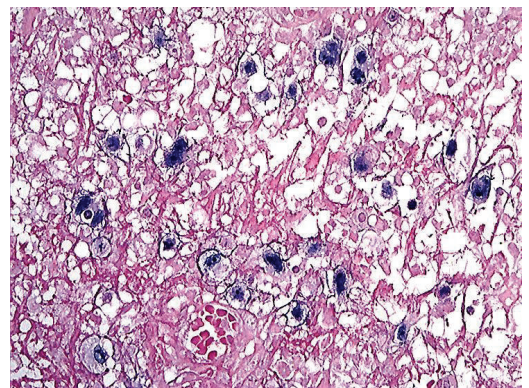

(e)

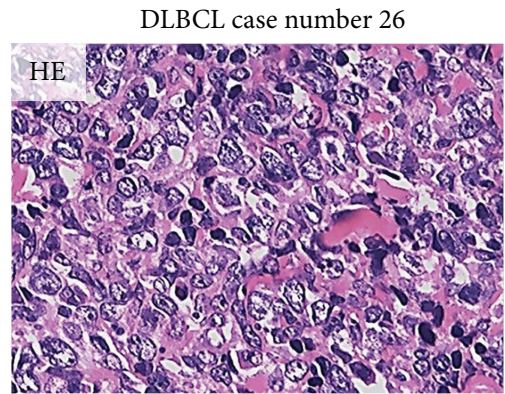

(c)

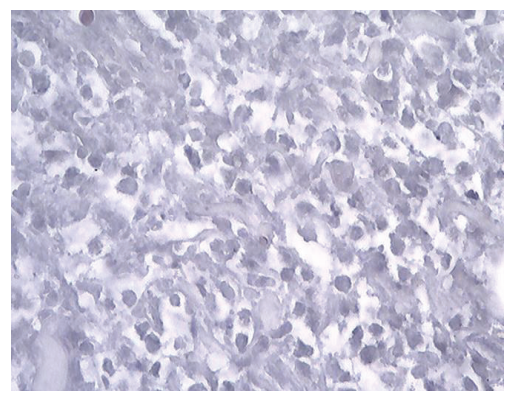

(f)

FIGURE 4: Distribution and intensity of EBER expression in MTX-/Age-EBV-LPDs and DLBCLs in biopsy specimens. ((a)-(c)) HE stain and ((d)-(f)) EBER by ISH (blackish color). EBER positive atypical lymphoid cells were sporadic diffuse in (d) MTX-LPD and (e) Age-LPD but were not verifiable in (f) DLBCL. EBER positive cells were of almost strong intensity in (d) MTX-LPD and (e) Age-LPD and were of weak or nonspecific intensity in (f) DLBCL ((a)-(f) original magnification, $\times 200)$.

at the $c-m y c$ and $I g H$ loci, which lead to reciprocal $c$ $m y c / I g H$ translocations, resulting in the development of Bcell lymphomas, such as Burkitt lymphoma in humans and plasmacytoma in mice [30]. AID protein is localized more in the cytoplasm than in the nucleus in normal and neoplastic $\mathrm{B}$-cells, and cytoplasmic AID protein relocates to the nucleus when pathological change occurs in B-cells $[31,32]$.

A recent in vitro study by Kim et al. [33] has shown that LMP-1 increases genomic instability through Egr-1mediated upregulation of AID in B-cell lymphoma cell lines. However, to our knowledge, no clinicopathological case study has examined the expression of LMP-1, AID, and Egr1 , including the distribution and density of positive cells, on LPDs. It is therefore important to clarify the expression pathway and distribution of positive cells in lesions of human tissues. We considered that AID positive cells would be more numerous in the EBV-driven LPDs than in DLBCLs showing a monotonous growth pattern. Therefore, we conducted an immunohistochemical study to investigate the relationship between LMP-1, AID, and Egr-1 expression in LPDs (MTX-/Age-related EBV-associated), including DLBCLs.

\section{Materials and Methods}

2.1. Tissue Samples. A total of 29 biopsy specimens were retrieved from the three hospitals to which the authors have contributed pathological diagnosis and were presented for investigation. Tissue samples from 17 cases of MTX-EBVLPD, 2 cases of Age-EBV-LPD, and 10 cases of DLBCL were used (Table 1). Sporadic-Burkitt lymphoma (sBL) [34], MTXLPD [35], Age-LPD [36], and oral squamous cell carcinoma (OSCC) were used as an overexpressing positive control for AID, LMP-1, EBV-encoded small RNA (EBER), and Egr-1. Ten samples of cervical lymph nodes (LNs) showing reactive lymphoid hyperplasia (RLH) were used as normal positive controls for AID, LMP-1, EBER, and Egr-1. Each section was prepared for immunohistochemical analysis (IHC) and in situ hybridization (ISH). The case study protocol was reviewed and approved by the Research Ethics Committee of Meikai University School of Dentistry (A0832, A1321).

2.2. Immunohistochemistry. Deparaffinized sections were immersed for $15 \mathrm{~min}$ at room temperature in absolute methanol containing $0.3 \% \mathrm{H}_{2} \mathrm{O}_{2}$ to block endogenous peroxidase activity and then treated with $2 \%$ bovine serum albumin for $15 \mathrm{~min}$ to block nonspecific reactions. After washing, they were incubated with an appropriately diluted mouse monoclonal antibody against human LMP-1 and rabbit polyclonal antibodies against AID and Egr-1 (Table 2). After washing, the sections were incubated with a prediluted anti-mouse or rabbit IgG antibody conjugated with peroxidase (Nichirei, Tokyo, Japan) for $30 \mathrm{~min}$ at room temperature. They were then immersed for $8 \mathrm{~min}$ in $0.05 \% 3,3^{\prime}$-diaminobenzidine tetrahydrochloride $(\mathrm{DAB})$ in $0.05 \mathrm{M}$ Tris- $\mathrm{HCl}$ buffer $(\mathrm{pH}$ 8.5) containing $0.01 \% \mathrm{H}_{2} \mathrm{O}_{2}$ and counterstained with Mayer's haematoxylin for $90 \mathrm{~s}$. 


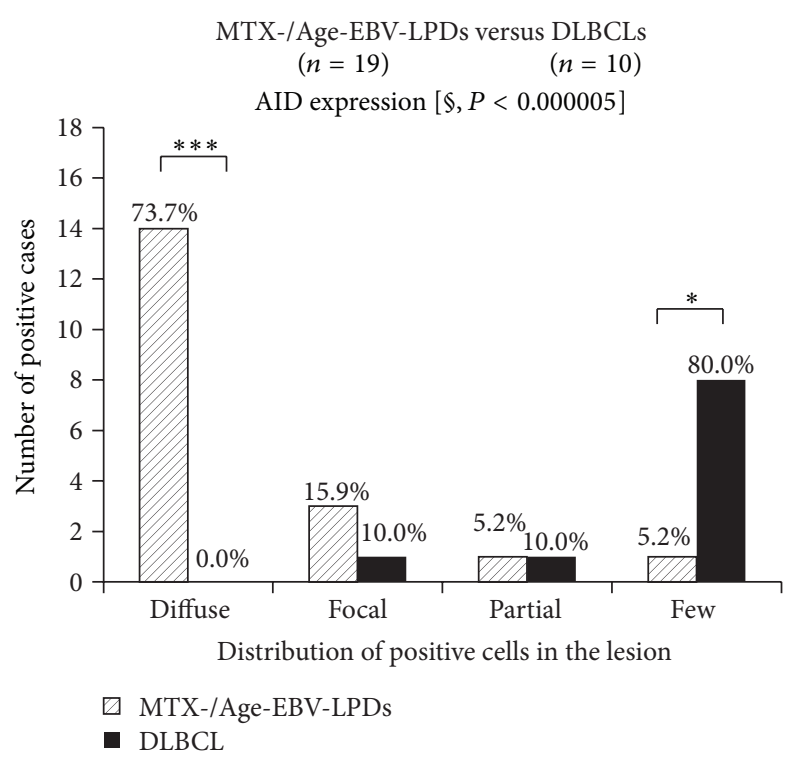

(a)

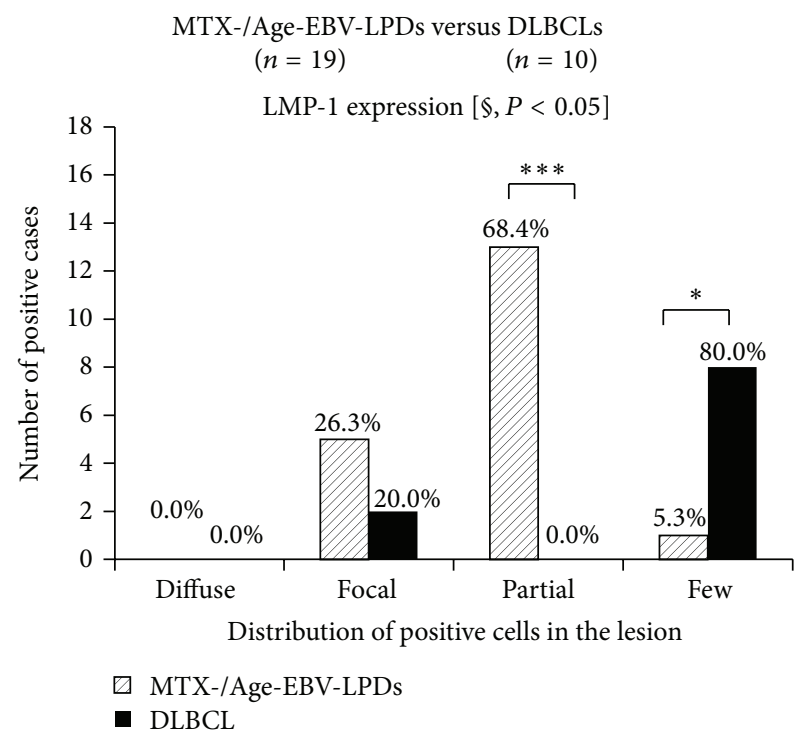

(b)

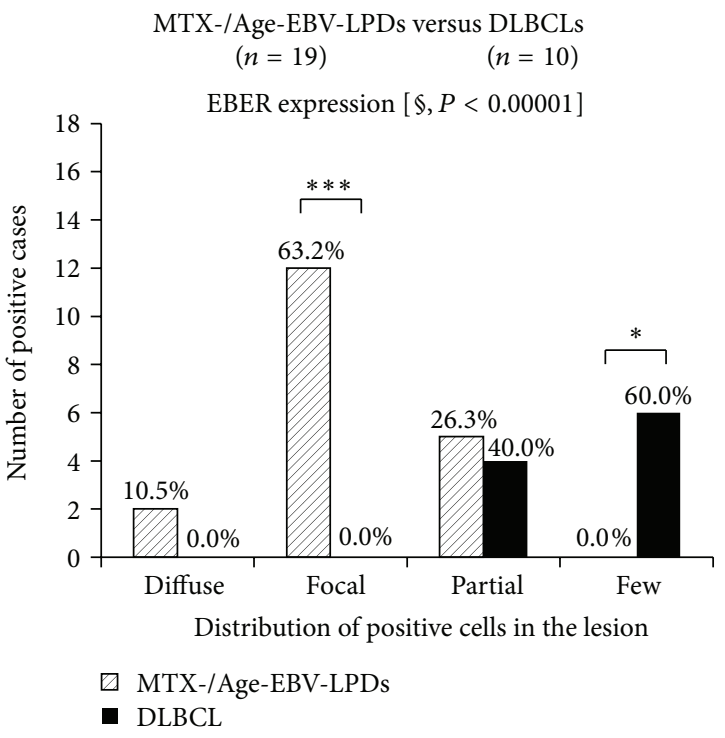

(c)

Figure 5: Distribution of AID, LMP, and EBER expression in MTX-/Age-EBV-LPDs and DLBCLs. ((a), (b), and (c)) The distribution of positive cells for AID, LMP, and EBER was more extensive in MTX-/Age-EBV-LPDs than in DLBCLs. $P$ values were examined by MannWhitney $U$ test $[\S]$ or Exact Binominal test $\left({ }^{*} P<0.05,{ }^{* *} P<0.01\right.$, and $\left.{ }^{* * *} P<0.001\right)$.

2.3. In Situ Hybridization. ISH for EBER oligonucleotides was performed to detect the presence of EBV small RNA in formalin-fixed paraffin-embedded sections using a hybridization kit (Dako, A/S, Denmark) in accordance with the manufacturer's instructions. Age-EBV-LPD was used as a positive control for EBER [36].

2.4. Assessment of AID, LMP-1, EBER, and Egr-1 Expression in Biopsy Specimens. Reactivity for each of the antigens and EBER was evaluated semiquantitatively using a light microscope (model BH2, Olympus Corp.). The distribution of the staining was categorized semiquantitatively according to the ratio of the positive area as follows: diffuse $(+++) \geqq 75 \%$; focal $(++)<75 \%$ to $\geqq 25 \%$; partial $(+)<25 \%$ to $\geqq 5 \%$; few $(-/ \pm)$ negative $/<5 \%$ or nonspecific. The intensity of the staining was categorized semiquantitatively as strong (S), moderate (M), weak $(\mathrm{W})$, or negative $(\mathrm{N})$ relative to each control specimen. AID intensity was compared with that in the sBL case sample used as a positive control [34] and expressed as strong (S) when higher or of the same intensity as that in $\mathrm{sBL}$, moderate (M) when lower than that in sBL or of the same intensity as that in RLH, weak (W) when lower than that in RLH, and negative $(\mathrm{N})$ in case of no staining or nonspecific staining. LMP-1 and EBER intensity were compared with those in 
MTX-/Age-EBV-LPDs versus DLBCLs [ $\$, P<0.000005]$

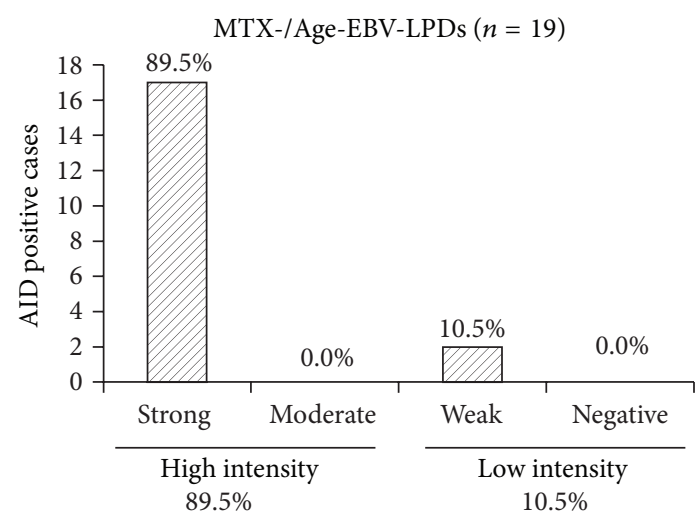

(a)

MTX-/Age-EBV-LPDs versus DLBCLs [ $\$, P<0.0005$ ]

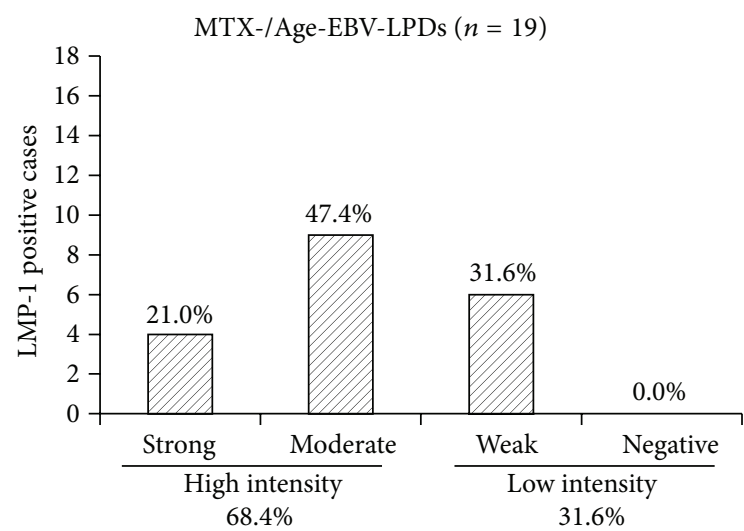

(c)

MTX-/Age-EBV-LPDs versus DLBCLs $[\S, P<0.0001]$

MTX-/Age-EBV-LPDs $(n=19)$

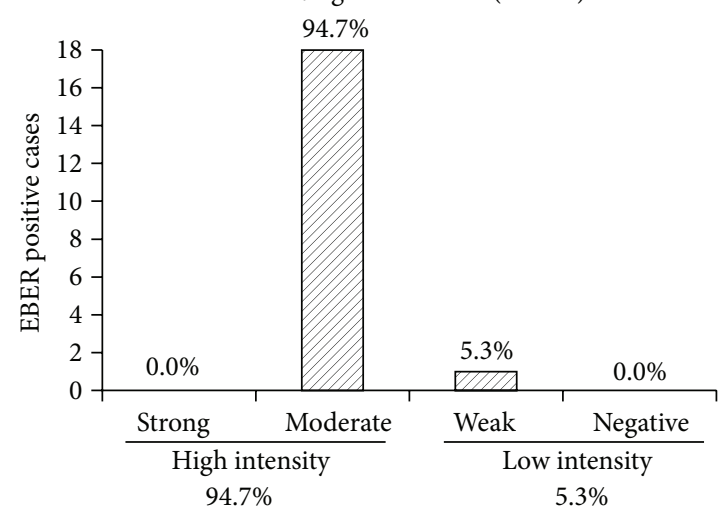

(e)
MTX-/Age-EBV-LPDs versus DLBCLs [ $\$, P<0.000005]$

DLBCLs $(n=10)$

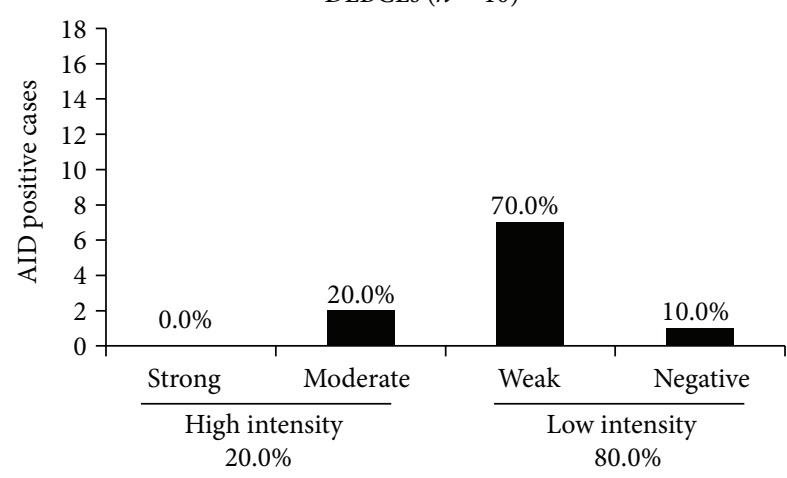

(b)

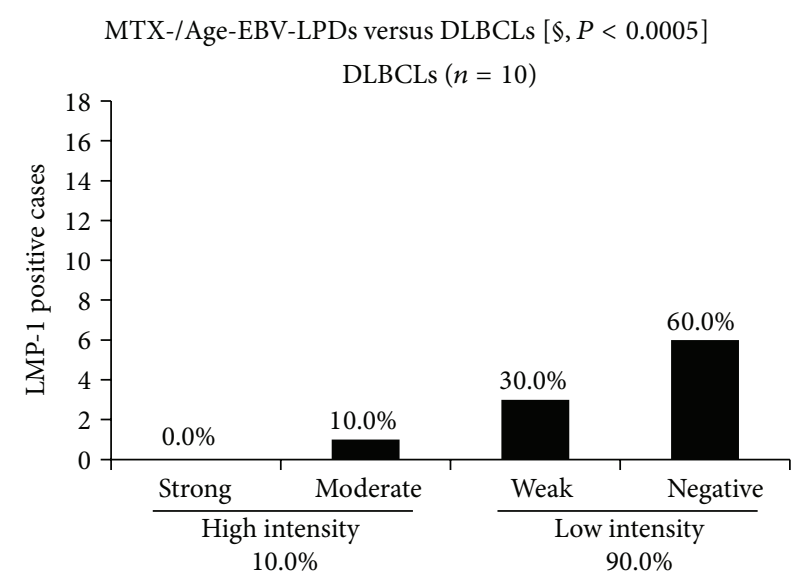

(d)

MTX-/Age-EBV-LPDs versus DLBCLs [ $\$, P<0.0001]$ DLBCLs $(n=10)$

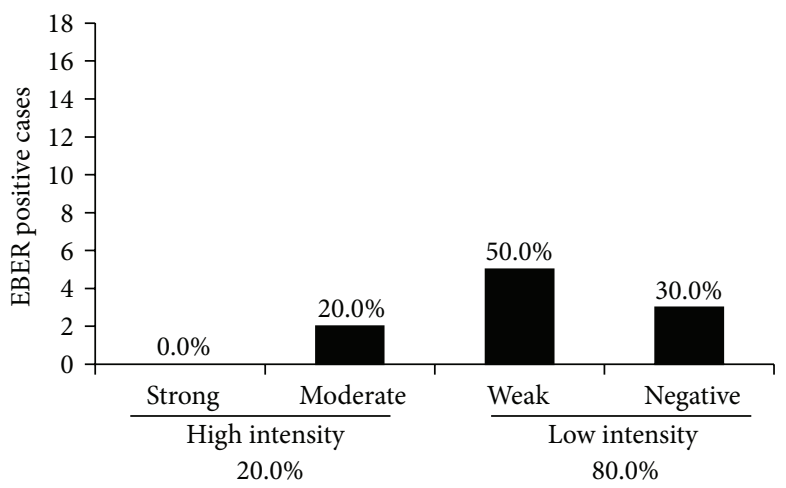

(f)

FIgURE 6: Intensity of AID, LMP-1, and EBER expression in MTX-/Age-EBV-LPDs and DLBCLs. High intensity rate of AID was higher in (a) MTX/Age-EBV-LPDs (89.5\%) than in (b) DLBCLs (20.0\%). Conversely, low intensity rate of AID was higher in (b) DLBCLs (80.0\%) than in (a) MTX/Age-EBV-LPDs (10.5\%). $P<0.000005$ by Mann-Whitney $U$ test [\$]. High intensity rate of LMP-1 was higher in (c) MTX/AgeEBV-LPDs (68.4\%) than in (d) DLBCLs (10.0\%). Conversely, low intensity rate of LMP-1 was higher in (d) DLBCLs (90.0\%) than in (c) MTX/Age-EBV-LPDs (31.6\%). $P<0.0005$ by Mann-Whitney $U$ test [ $\S$ ]. High intensity rate of EBER was higher in (e) MTX/Age-EBV-LPDs (94.7\%) than in (f) DLBCLs (20.0\%). Conversely, low intensity rate of EBER was higher in (f) DLBCLs (80.0\%) than in (e) MTX/Age-EBVLPDs (5.3\%). $P<0.0001$ by Mann-Whitney $U$ test [\$]. 


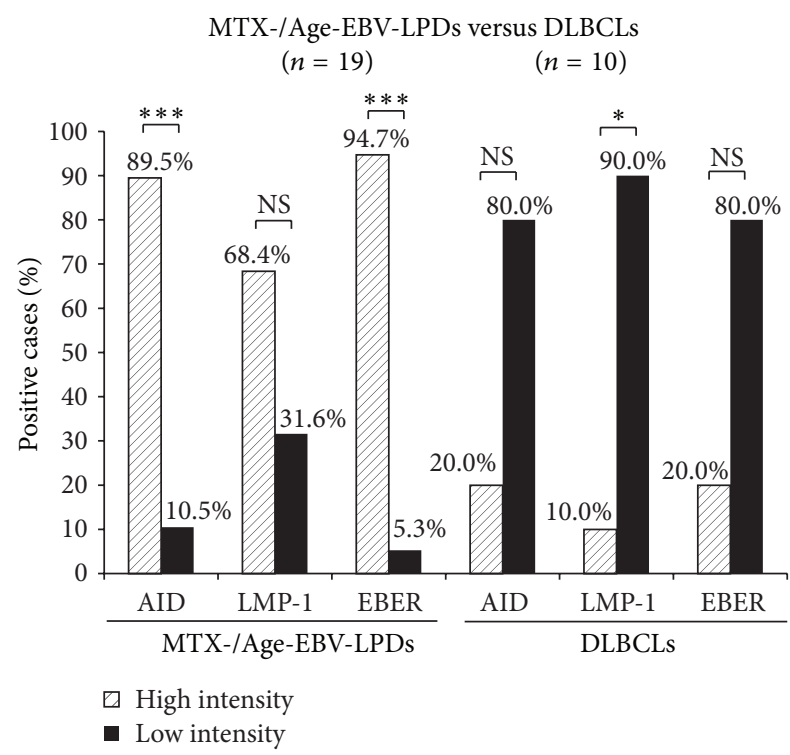

FIgURE 7: Comparison of the intensity of AID, LMP-1, and EBER expression between MTX/Age-EBV-LPDs and DLBCLs. High intensity showed strongly and moderately positive cases, and low intensity showed weakly positive and negative cases. Although a high intensity of expression (AID, LMP-1, and EBER) was greater in MTX-/Age-EBV-LPDs than in DLBCLs, a low intensity of those was smaller in the former than in the latter. $P$ values were examined by Exact Binominal test $\left({ }^{*} P<0.05,{ }^{* *} P<0.01\right.$, and $\left.{ }^{* * *} P<0.001\right)$. NS: not significant.

MTX-LPD and Age-EBV-LPD used as a positive control $[35,36]$ and evaluated in the same manner as those for AID. Egr-1 intensity was compared with that in OSCC used as a positive control and evaluated in the same manner as that for AID.

2.5. Statistical Analysis. The significance of differences between the mean values was determined by using the MannWhitney $U$ test or Exact Binominal test for comparing two categories. The accepted level of significance was $P<0.05$.

\section{Results}

Strong AID, LMP-1, EBER, and Egr-1 reactivity were observed in overexpressing positive control specimens in sBL, MTXLPD, Age-LPD, and OSCC by IHC and ISH (Figures 1(a)1(d)). Moderate AID, LMP-1, EBER, and Egr-1 reactivity were observed in normal positive control specimens RLM by IHC and ISH (Figures 1(e)-1(h)). AID expression was diffuse and strongly positive in MTX-/Age-EBV-LPDs (Figures 2(a), 2(b), 2(d), and 2(e)) and was few and moderately positive in DLBCLs (Figures 2(c) and 2(f)). Although LMP-1 expression was diffuse and strongly positive in MTX-/Age-EBV-LPDs (Figures 3(a), 3(b), 3(d), and 3(e)), the expression was few and weakly positive in DLBCLs (Figures 3(c) and 3(f)). EBER expression was sporadic diffuse and strongly positive in MTX-/Age-EBV-LPDs (Figures 4(a), 4(b), 4(d), and 4(e)), while EBER reactivity was negative in DLBCLs (Figures 4(c) and 4(f)). Expression of AID, LMP-1, and EBER was higher in MTX-/Age-EBV-LPDs than in DLBCLs. Staining patterns, AID, LMP-1, and EBER, were compared between different lesion types (Table 1).

The distribution of AID $(P<0.000005)$, LMP-1 $(P<$ $0.05)$, and EBER $(P<0.00001)$ expression was significantly more extensive in the MTX-/Age-EBV-LPDs than in the DLBCLs (Figures 5(a)-5(c)). In addition, AID expression was significantly more intense in MTX-/Age-EBV-LPDs than in DLBCLs $(P<0.000005)$ (Figures 6(a) and 6(b)), and expression of LMP-1 $(P<0.0005)$ (Figures 6(c) and 6(d)) and $\operatorname{EBER}(P<0.0001)$ was more intense in MTX/Age-EBV-LPDs than in DLBCLs (Figures 6(e) and 6(f)). The high intensity (strong and moderate) of AID, LMP-1, and EBER expression was greater in MTX/Age-EBV-LPDs $(89.5 \%, 68.4 \%$, and $94.7 \%)$ than in DLBCLs $(20.0 \%, 10.0 \%$, and $20.0 \%$ ) (Figures 6 and 7). Conversely, the low intensity (weak and negative) of AID, LMP-1, and EBER expression was greater in DLBCLs $(80.0 \%, 90.0 \%$, and $80.0 \%)$ than in MTX/Age-EBV-LPDs (10.5\%, 31.6\%, and 5.3\%) (Figures 6 and 7). In MTX-/Age-EBV-LPDs, the intensity of AID, LMP-1, and EBER expression was stronger than in DLBCLs (Figure 7). Egr-1 expression was diffuse and strongly positive in MTX-/Age-EBV-LPDs (Figures 8(a)-8(c)) and was a positive variety in the DLBCLs (Figures $8(\mathrm{~d})-8(\mathrm{f})$ ). Distribution of Egr-1 expression was significantly more extensive in MTX-/Age-EBV-LPDs than in the DLBCLs $(P<0.001)$ (Figure 9(a)). The intensity of Egr-1 was significantly different between MTX-/Age-EBV-LPDs and DLBCLs $(P<0.01)$ (Figures 9(b) and 9(c)). Although the high intensity of Egr1 expression was comparable rate in both MTX-/Age-EBVLPDs (94.4\%) and DLBCLs (80.0\%), strong intensity was higher in MTX-/Age-EBV-LPDs (83.3\%) (Figure 9(b)) than in DLBCLs (30.0\%) (Figure 9(c)).

\section{Discussion}

Immunohistochemical analysis in this study revealed that the expression of AID, LMP-1, and Egr-1 had a much more diffuse distribution and was stronger in intensity in LPD than in DLBCL cases. Furthermore, LPD cases showed a more diffuse distribution and stronger intensity of EBER-ISH than DLBCL cases.

EBV is associated with a variety of LPDs and malignant lymphomas [1,3-5]. EBV-driven B-cell LPDs occur in patients who are immunosuppressed due to primary immune deficiency, HIV infection, or organ transplantation or patients who have received other treatments including methotrexate and tumor necrosis factor- $\alpha$ antagonists [10, 11]. Primary EBV infection is usually asymptomatic and leads to latent infection in memory B-cells, which do not permit viral replication [37]. Although newly infected naive B-cells have the phenotypes of transformed cells, they are controlled by both EBV-specific cytotoxic T lymphocytes and natural killer cells unless immunity is suppressed $[37,38]$. In immunocompromised hosts, transformed cells become proliferating blasts that can result in symptomatic disease, such as immunodeficiency-associated LPD $[1,10,37,38]$. LPD is 


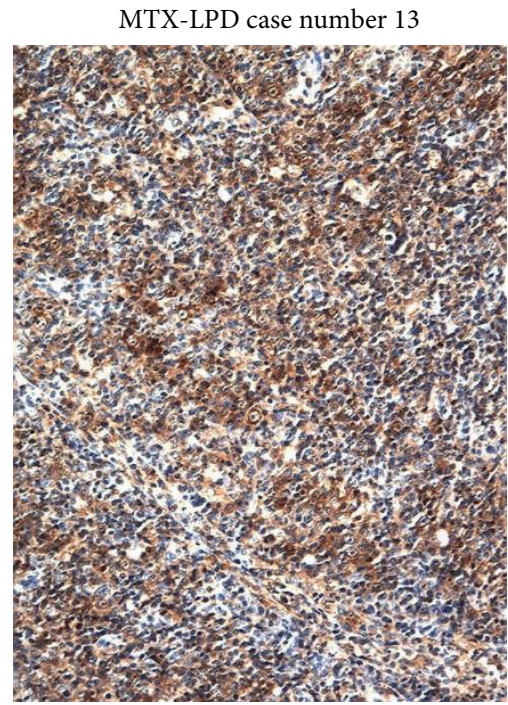

(a)

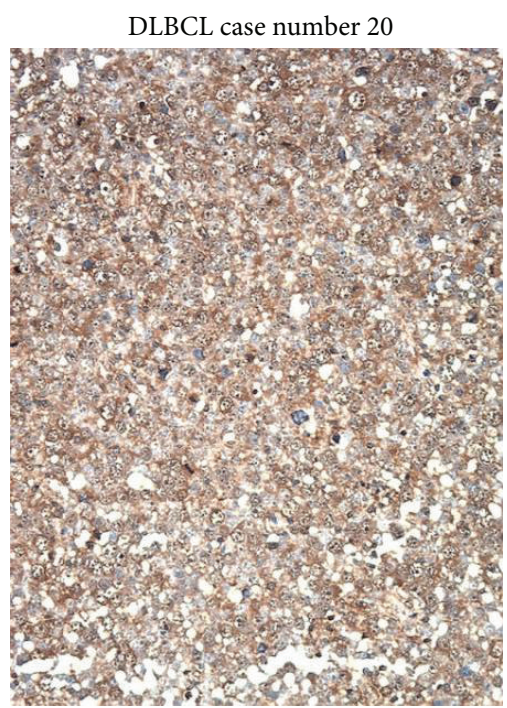

(d)
MTX-LPD case number 8

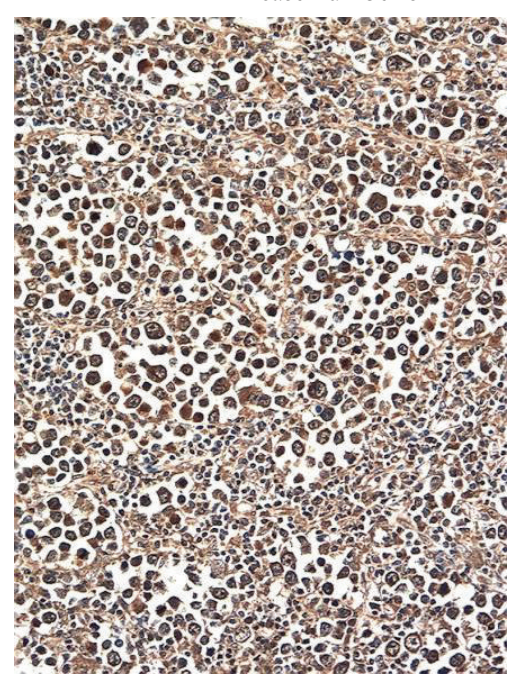

(b)

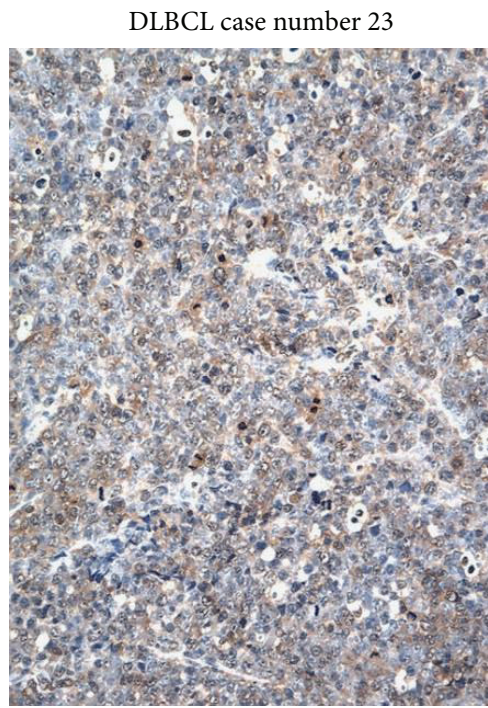

(e)

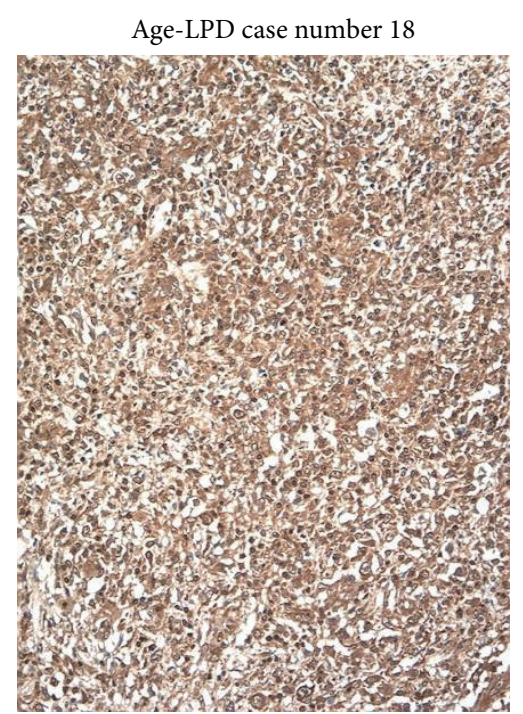

(c)

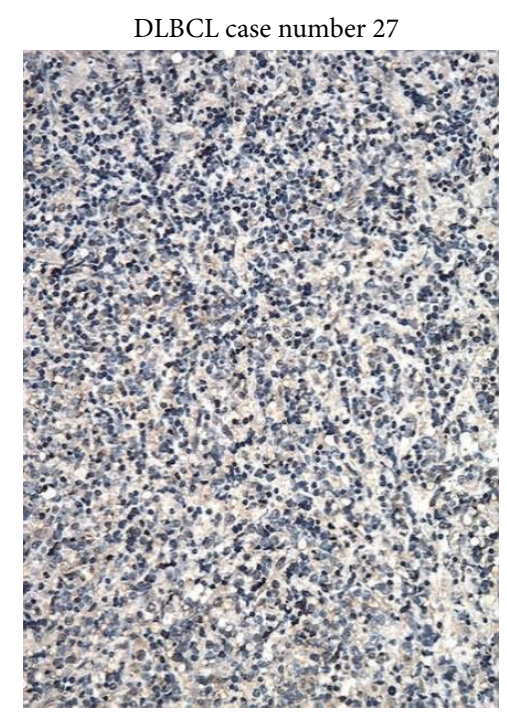

(f)

FIGURE 8: Distribution and intensity of Egr-1 expression in MTX-/Age-LPDs and DLBCLs in biopsy specimens. Egr-1 positive cells (brownish color) were diffuse and of strong intensity in ((a), (b)) MTX-LPDs and (c) Age-LPD and were a variety in ((d)-(f)) DLBCLs ((a)-(f) original magnification $\times 100)$.

characterized pathologically by focal or diffuse proliferation of atypical large B-cells including Reed-Sternberg-like cells with reactive components, which pose a diagnostic problem for pathologists. The spectrum of EBV-LPD is broad, ranging from benign polyclonal reactivation lesions to monoclonal EBV-DLBCL [39].

The major EBV-encoded LMP-1 is an integral membrane protein, which activates signaling pathways such as that involving NF- $\kappa \mathrm{B}$, which increases B-cell survival and induces transformation [12-16] by inducing antiapoptotic protein [17-19]. An in vitro study has reported that EBV-infected cells undergo hypermutation or switching of recombination via AID upregulation [20], and EBV-induced AID is also associated with oncogene mutations, which contribute to lymphomagenesis [21]. In a mouse bone marrow transplantation model, AID overexpression was reported to promote B-cell lymphomagenesis [40]. Although the relationship between LMP-1 and lymphomagenesis has been relatively well established, the molecular mechanisms underlying AID induction remain to be fully clarified. Recently, Kim et al. have reported that LMP-1 increases genomic instability through Egr-1mediated upregulation of AID in B-cell lymphoma [18]. The Egr-1 gene (also named zif268, NGFI-A, or Krox24) encodes an $80 \mathrm{kDa}$ DNA-binding transcription factor [41]. Egr-1 is an exceptionally multifunctional transcription factor. In response to growth factors and cytokine signaling, Egr-1 regulates cell growth, differentiation, and apoptosis [42]. Egr1 has been associated with EBV infection, a human gamma herpes virus closely associated with several lymphoid and epithelial malignancies [43]. First, Egr-1 is upregulated when 


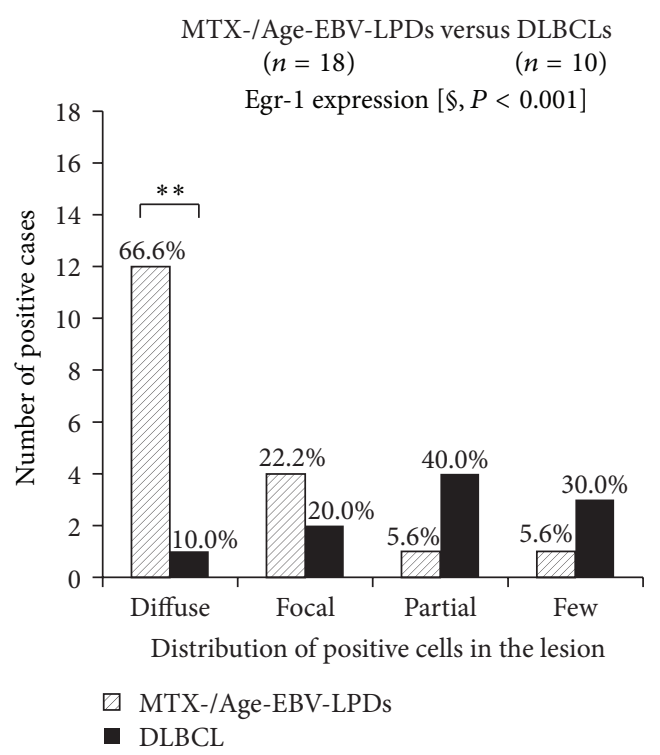

(a)

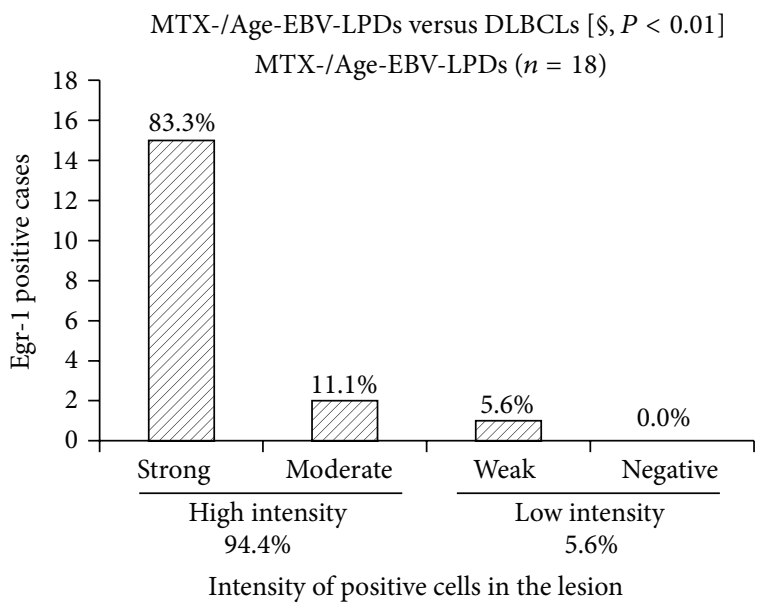

(b)

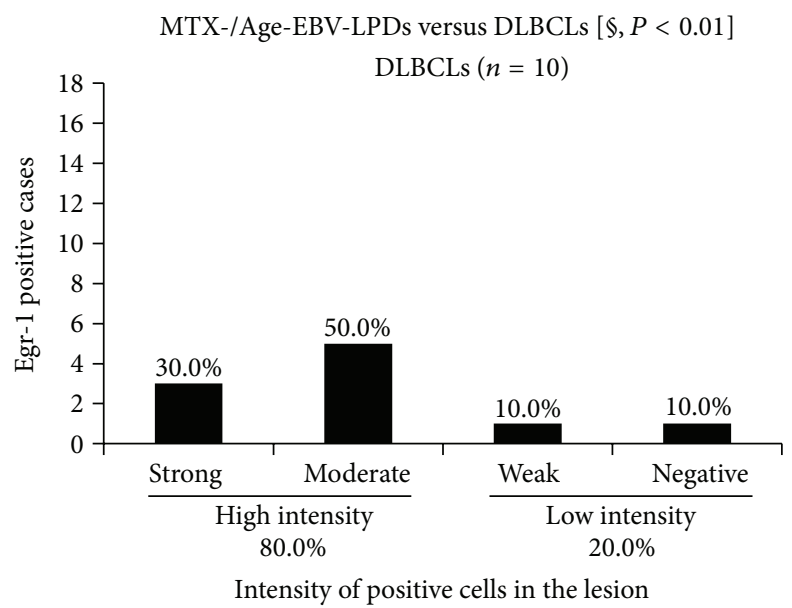

(c)

FIGURE 9: Distribution and intensity of Egr-1 expression in MTX-/Age-EBV-LPDs and DLBCLs. (a) Distribution of Egr-1-positive cells was more extensive in MTX-/Age-EBV-LPDs than in DLBCLs $(P<0.001)$. (a) In diffuse category, distribution of Egr-1 was significantly greater in MTX-/Age-EBV-LPDs (66.6\%) than in DLBCLs (10.0\%). ((b), (c)) Although the intensity of Egr-1 expression was high in both MTX/AgeEBV-LPDs (94.4\%) and DLBCLs (80.0\%), in the strong category, it was greater in the former (83.3\%) than in the latter (30.0\%). $P$ values were examined by Mann-Whitney $U$ test $[\S]$ or Exact Binominal test $\left({ }^{*} P<0.05,{ }^{* *} P<0.01\right.$, and $\left.{ }^{* * *} P<0.001\right)$.

EBV interacts with B lymphocytes at the initial infection stage, and constitutive expression of Egr-1 correlates with certain types of EBV latency in B-lymphoid cell lines [44]. EBV reactivation is associated with upregulation of Egr-1, and Egr-1 can be induced as an EBV lytic transactivator [45]. However, there are no reports of any clinicopathological studies on LMP-1, AID, and Egr-1 in samples of human tissue. Therefore, we examined the density and distribution of AID, LMP-1, EBER, and Egr-1 in 19 cases of LPD and 10 cases of DLBCL.

The distribution of AID, LMP-1, and EBER expression was more extensive in patients with LPD than in patients with DLBCL. The intensity of AID, LMP-1, and EBER expression was higher in LPD (89.5\%, 68.4\%, and 94.7\%) than in DLBCL
$(20.0 \%, 10.0 \%$, and $20.0 \%)$ patients (Figure 7). Although a higher intensity of expression was seen in LPD (94.4\%) and DLBCL (80\%), the intensity of Egr-1 expression was stronger in the former (83.3\%) than in the latter (30.0\%) (Figures 9(b) and 9(c)). These in vivo results partly supported the previous in vitro study by Kim et al. [18] and suggest that overexpression of AID in LPDs may be one process in the course of tumorigenic transformation.

The factor responsible for the lack of lymphoid tissue involvement in oral areas in patients with primary lymphoma/LPD is unclear, but there may be some association with bacteria in and around the teeth, together with chronic inflammation such as apical and marginal periodontitis. The copy number of EBV-DNA in subgingival plaque is associated 
with the presence of some periodontal bacteria [46]. A recent study has shown that periodontal disease could act as a risk factor for HIV reactivation [47] and similarly induce EBV reactivation [48]. Thus, there may be a relationship between AID, LMP-1, and Egr-1 expression in EBV-infected B-cells. Further studies, including the head and neck, will be needed to confirm the causal link between oral bacteria and EBVpositive lymphoma/LPDs of the oral cavity.

These results suggest that increased AID expression in LPDs may be part of the process of lymphomagenesis, thereby further increasing the survival of genetically destabilized Bcells. The reason why AID, LMP-1, and EBER were expressed more in the EBV related LPDs compared to DLBCL could be either the EBV infection or immunosuppression that is predominant in age-related lymphoma or in autoimmune diseases of patients taking methotrexate. The intensity and distribution of AID expression may be an indicator for differentiating EBV-driven LPDs from DLBCLs.

\section{Conflict of Interests}

The authors declare that there is no conflict of interests regarding the publication of this paper.

\section{References}

[1] B. Borisch, M. Raphael, S. H. Swerdlow et al., "Immunodeficiency associated lymphoproliferative disorders," in World Health Organization Classification of Tumours: Pathology and Genetics of Tumours of Haematopoietic and Lymphoid Tissues, E. S. Jaffe, N. L. Harris, H. Stein, and J. W. Vardiman, Eds., pp. 255-271, International Agency for Research on Cancer, Lyon, France, 2001.

[2] S. Nakamura, E. S. Jaffe, and S. H. Swerdlow, "BV-positive diffuse large B-cell lymphoma of the elderly," in World Health Organization Classification of Tumours of Haematopoietic and Lymphoid Tissues, S. J. Swerdlow, E. Campo, N. L. Harris et al., Eds., pp. 243-244, IARC, Lyon, France, 2008.

[3] R. F. Ambinder, "Epstein-Barr virus-associated lymphoproliferative disorders," Reviews in Clinical and Experimental Hematology, vol. 7, no. 4, pp. 362-374, 2003.

[4] J. Diebold, E. S. Jaffe, M. Raphael, and R. A. Warnke, "Burkitt lymphoma," in Pathology and Genetics of Tumours of Haematopoietic and Lymphoid Tissues, E. S. Jaffe, N. L. Harris, H. Stein, and J. W. Vardiman, Eds., World Health Organization Classification of Tumours, pp. 181-185, IARC, Lyon, France, 2001.

[5] J. K. C. Chan, E. S. Jaffe, and E. Ralfkiaer, "Extranodal NK/Tcell lymphoma, nasal type," in World Health Organization Classification of Tumours. Pathology and Genetics of Tumours of Haematopoietic and Lymphoid Tissues, E. S. Jaffe, N. L. Harris, H. Stein, and J. W. Vardiman, Eds., pp. 204-207, International Agency for Research on Cancer (IARC), Lyon, France, 2001.

[6] R. Fåhraeus, H. L. Fu, I. Ernberg et al., "Expression of EpsteinBarr virus-encoded proteins in nasopharyngeal carcinoma," International Journal of Cancer, vol. 42, no. 3, pp. 329-338, 1988.

[7] L. M. Weiss, L. A. Movahed, R. A. Warnke, and J. Sklar, "Detection of Epstein-Barr viral genomes in Reed-Sternberg cells of Hodgkin's disease," The New England Journal of Medicine, vol. 320 , no. 8, pp. 502-506, 1989.
[8] D. Shibata and L. M. Weiss, "Epstein-Barr virus-associated gastric adenocarcinoma," American Journal of Pathology, vol. 140, no. 4, pp. 769-774, 1992.

[9] J. M. Kwon, Y. H. Park, J. H. Kang et al., "The effect of EpsteinBarr virus status on clinical outcome in Hodgkin's lymphoma," Annals of Hematology, vol. 85, no. 7, pp. 463-468, 2006.

[10] E. S. Jaffe, N. L. Harris, S. J. Swerdlow et al., "Immunodeficiencyassociated lymphoproliferative disorder," in World Health Organization Classification of Tumors of Haematopoietic and Lymphoid Tissues, S. J. Swerdlow, E. Campo, N. L. Harris et al., Eds., pp. 335-351, IARC, Lyon, France, 2008.

[11] T. Oyama, K. Ichimura, R. Suzuki et al., "Senile EBV ${ }^{+}$B-cell lymphoproliferative disorders: a clinicopathologic study of 22 patients," The American Journal of Surgical Pathology, vol. 27, no. 1, pp. 16-26, 2003.

[12] P. G. Murray, L. S. Young, M. Rowe, and J. Crocker, "Immunohistochemical demonstration of the Epstein-Barr virusencoded latent membrane protein in paraffin sections of Hodgkin's disease," The Journal of Pathology, vol. 166, no. 1, pp. $1-5,1992$.

[13] M. Peng and E. Lundgren, "Transient expression of the EpsteinBarr virus LMP1 gene in human primary B cells induces cellular activation and DNA synthesis," Oncogene, vol. 7, no. 9, pp. 1775$1782,1992$.

[14] D. S. Huen, S. A. Henderson, D. Croom-Carter, and M. Rowe, "The Epstein-Barr virus latent membrane protein-1 (LMP1) mediates activation of NF- $\kappa$ B and cell surface phenotype via two effector regions in its carboxy-terminal cytoplasmic domain," Oncogene, vol. 10, no. 3, pp. 549-560, 1995.

[15] O. Gires, U. Zimber-Strobl, R. Gonnella et al., "Latent membrane protein 1 of Epstein-Barr virus mimics a constitutively active receptor molecule," The EMBO Journal, vol. 16, no. 20, pp. 6131-6140, 1997.

[16] E. D. C. McFarland, K. M. Izumi, and G. Mosialos, "EpsteinBarr virus transformation: involvement of latent membrane protein 1-mediated activation of NF- $\kappa$ B," Oncogene, vol. 18, no. 49, pp. 6959-6964, 1999.

[17] K. R. N. Baumforth, L. S. Young, K. J. Flavell, C. Constandinou, and P. G. Murray, "The Epstein-Barr virus and its association with human cancers," Journal of Clinical Pathology-Molecular Pathology, vol. 52, no. 6, pp. 307-322, 1999.

[18] J. H. Kim, W. S. Kim, J. H. Kang, H.-Y. Lim, Y.-H. Ko, and C. Park, "Egr-1, a new downstream molecule of Epstein-Barr virus latent membrane protein 1," FEBS Letters, vol. 581, no. 4, pp. 623-628, 2007.

[19] J. H. Kim, W. S. Kim, and C. Park, "SNARK, a novel downstream molecule of EBV latent membrane protein 1, is associated with resistance to cancer cell death," Leukemia and Lymphoma, vol. 49, no. 7, pp. 1392-1398, 2008.

[20] B. He, N. Raab-Traub, P. Casali, and A. Cerutti, "EBV-encoded latent membrane protein 1 cooperates with BAFF/BLyS and APRIL to induce $\mathrm{T}$ cell-independent Ig heavy chain class switching," The Journal of Immunology, vol. 171, no. 10, pp. 52155224, 2003.

[21] M. Epeldegui, Y. P. Hung, A. McQuay, R. F. Ambinder, and O. Martínez-Maza, "Infection of human B cells with EpsteinBarr virus results in the expression of somatic hypermutationinducing molecules and in the accrual of oncogene mutations," Molecular Immunology, vol. 44, no. 5, pp. 934-942, 2007.

[22] M. Muramatsu, V. S. Sankaranand, S. Anant et al., "Specific expression of activation-induced cytidine deaminase (AID), 
a novel member of the RNA-editing deaminase family in germinal center B cells," The Journal of Biological Chemistry, vol. 274, no. 26, pp. 18470-18476, 1999.

[23] P. Revy, T. Muto, Y. Levy et al., "Activation-induced cytidine deaminase (AID) deficiency causes the autosomal recessive form of the hyper-IgM syndrome (HIGM2)," Cell, vol. 102, no. 5, pp. 565-575, 2000.

[24] M. Muramatsu, K. Kinoshita, S. Fagarasan, S. Yamada, Y. Shinkai, and T. Honjo, "Class switch recombination and hypermutation require activation-induced cytidine deaminase (AID), a potential RNA editing enzyme," Cell, vol. 102, no. 5, pp. 553-563, 2000.

[25] V. G. De Yábenes and A. R. Romiro, "Activation-induced deaminase: light and dark sides," Trends in Molecular Medicine, vol. 12, no. 9, pp. 432-439, 2006.

[26] S. Longerich, U. Basu, F. Alt, and U. Storb, "AID in somatic hypermutation and class switch recombination," Current Opinion in Immunology, vol. 18, no. 2, pp. 164-174, 2006.

[27] R. K. Delker, S. D. Fugmann, and F. N. Papavasiliou, "A comingof-age story: activation-induced cytidine deaminase turns 10," Nature Immunology, vol. 10, no. 11, pp. 1147-1153, 2009.

[28] M. Kuraoka, L. McWilliams, and G. Kelsoe, "AID expression during B-cell development: searching for answers," Immunologic Research, vol. 49, no. 1-3, pp. 3-13, 2011.

[29] S.-R. Park, "Activation-induced cytidine deaminase in B cell immunity and cancers," Immune Network, vol. 12, no. 6, pp. 230239, 2012.

[30] D. F. Robbiani and M. C. Nussenzweig, "Chromosome translocation, B cell lymphoma, and activation-induced cytidine deaminase," Annual Review of Pathology: Mechanisms of Disease, vol. 8, pp. 79-103, 2013.

[31] L. Pasqualucci, R. Guglielmino, J. Houldsworth et al., "Expression of the AID protein in normal and neoplastic B cells," Blood, vol. 104, no. 10, pp. 3318-3325, 2004.

[32] G. Cattoretti, M. Büttner, R. Shaknovich, E. Kremmer, B. Alobeid, and G. Niedobitek, "Nuclear and cytoplasmic AID in extrafollicular and germinal center B cells," Blood, vol. 107, no. 10, pp. 3967-3975, 2006.

[33] J. H. Kim, W. S. Kim, and C. Park, "Epstein-Barr virus latent membrane protein 1 increases genomic instability through Egr-1-mediated up-regulation of activation-induced cytidine deaminase in B-cell lymphoma," Leukemia and Lymphoma, vol. 54, no. 9, pp. 2035-2040, 2013.

[34] K. Kikuchi, H. Inoue, Y. Miyazaki et al., "Adult sporadic burkitt lymphoma of the oral cavity: a case report and literature review," Journal of Oral and Maxillofacial Surgery, vol. 70, no. 12, pp. 2936-2943, 2012.

[35] K. Kikuchi, Y. Miyazaki, A. Tanaka et al., "Methotrexaterelated Epstein-Barr Virus (EBV)-associated lymphoproliferative disorder-so-called 'Hodgkin-like lesion'-of the oral cavity in a patient with rheumatoid arthritis," Head and Neck Pathology, vol. 4, no. 4, pp. 305-311, 2010.

[36] K. Kikuchi, S. Fukunaga, H. Inoue et al., "A case of age-related Epstein-Barr virus (EBV)-associated B cell lymphoproliferative disorder, so-called polymorphous subtype, of the mandible, with a review of the literature," Head and Neck Pathology, vol. 7, no. 2, pp. 178-187, 2013.

[37] H. Kimura, Y. Ito, R. Suzuki, and Y. Nishiyama, "Measuring Epstein-Barr virus (EBV) load: the significance and application for each EBV-associated disease," Reviews in Medical Virology, vol. 18, no. 5, pp. 305-319, 2008.
[38] J. I. Cohen, "Epstein-Barr virus infection," The New England Journal of Medicine, vol. 343, no. 7, pp. 481-492, 2000.

[39] Y. Shimoyama, N. Asano, M. Kojima et al., "Age-related EBV-associated B-cell lymphoproliferative disorders: diagnostic approach to a newly recognized clinicopathological entity," Pathology International, vol. 59, no. 12, pp. 835-843, 2009.

[40] Y. Komeno, J. Kitaura, N. Watanabe-Okochi et al., "AIDinduced T-lymphoma or B-leukemia/lymphoma in a mouse BMT model," Leukemia, vol. 24, no. 5, pp. 1018-1024, 2010.

[41] J. Milbrandt, "A nerve growth factor-induced gene encodes a possible transcriptional regulatory factor," Science, vol. 238, no. 4828, pp. 797-799, 1987.

[42] S. Bhattacharyya, F. Fang, W. Tourtellotte, and J. Varga, "Egr-1: new conductor for the tissue repair orchestra directs harmony (regeneration) or cacophony (fibrosis)," Journal of Pathology, vol. 229, no. 2, pp. 286-297, 2013.

[43] A. B. Rickinson and E. Kieff, "Epstein-Barr virus," in Fields Virology, D. M. Knipe and P. M. Howley, Eds., pp. 2575-2627, Lippincott Williams \& Wilkins, Philadelphia, Pa, USA, 4th edition, 2001.

[44] A. Calogero, L. Cuomo, M. D’Onofrio et al., "Expression of Egr-1 correlates with the transformed phenotype and the type of viral latency in EBV genome positive lymphoid cell lines," Oncogene, vol. 13, no. 10, pp. 2105-2112, 1996.

[45] Y. Chang, H. H. Lee, Y. T. Chen et al., "Induction of the early growth response 1 gene by Epstein-Barr virus lytic transactivator Zta," Journal of Virology, vol. 80, no. 15, pp. 7748-7755, 2006.

[46] D. R. Dawson III, C. Wang, R. J. Danaher et al., "Real-time polymerase chain reaction to determine the prevalence and copy number of epstein-barr virus and cytomegalovirus DNA in subgingival plaque at individual healthy and periodontal disease sites," Journal of Periodontology, vol. 80, no. 7, pp. 11331140, 2009.

[47] K. Imai, K. Ochiai, and T. Okamoto, "Reactivation of latent HIV-1 infection by the periodontopathic bacterium Porphyromonas gingivalis involves histone modification," The Journal of Immunology, vol. 182, no. 6, pp. 3688-3695, 2009.

[48] K. Imai, H. Inoue, M. Tamura et al., “The periodontal pathogen Porphyromonas gingivalis induces the Epstein-Barr virus lytic switch transactivator ZEBRA by histone modification," Biochimie, vol. 94, no. 3, pp. 839-846, 2012. 


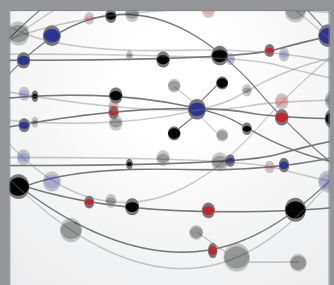

The Scientific World Journal
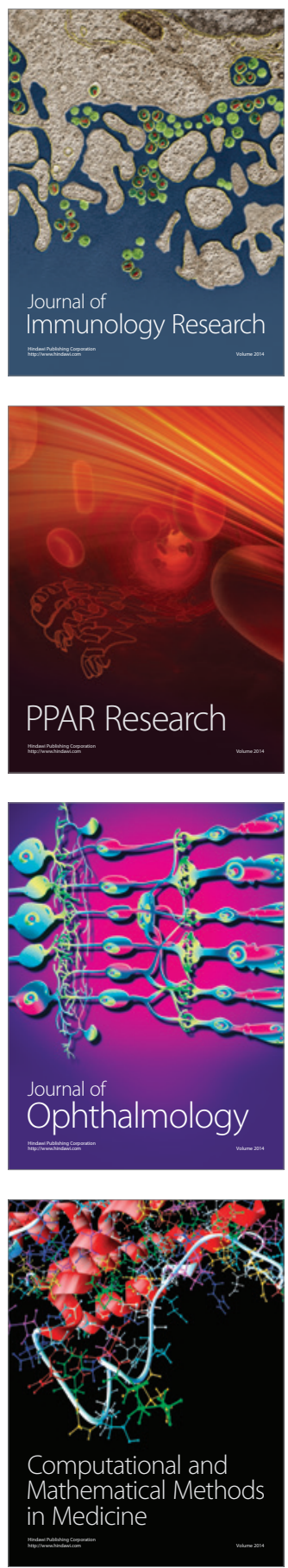

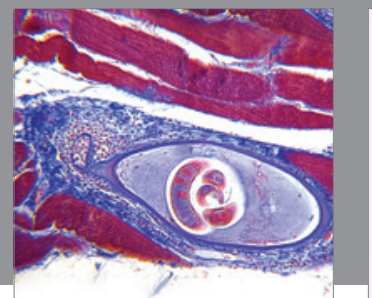

Gastroenterology

Research and Practice
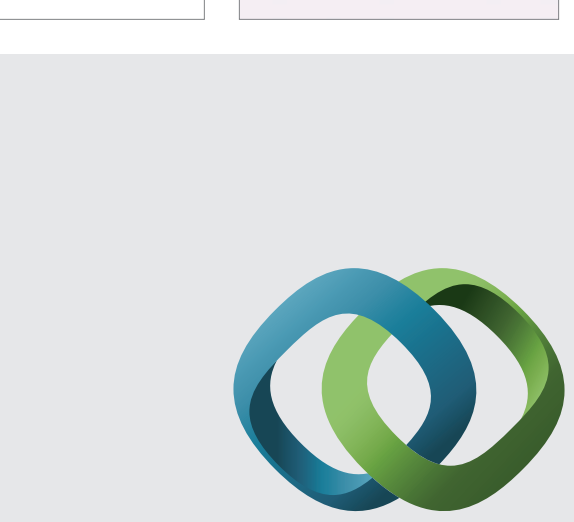

\section{Hindawi}

Submit your manuscripts at

http://www.hindawi.com
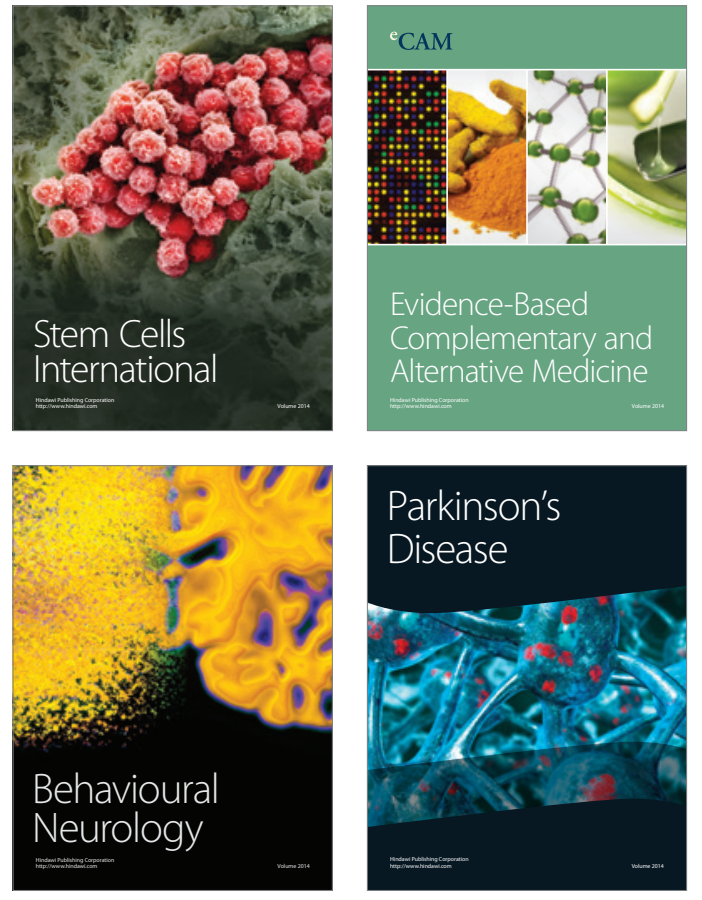
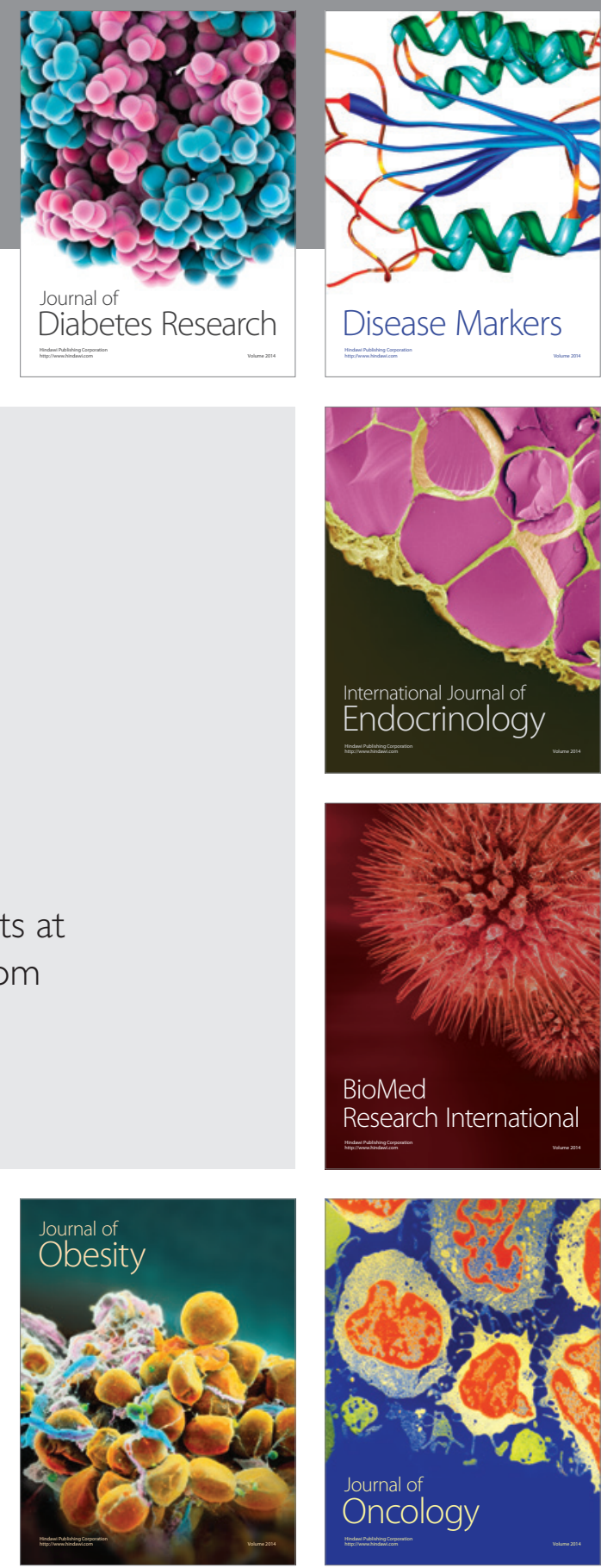

Disease Markers
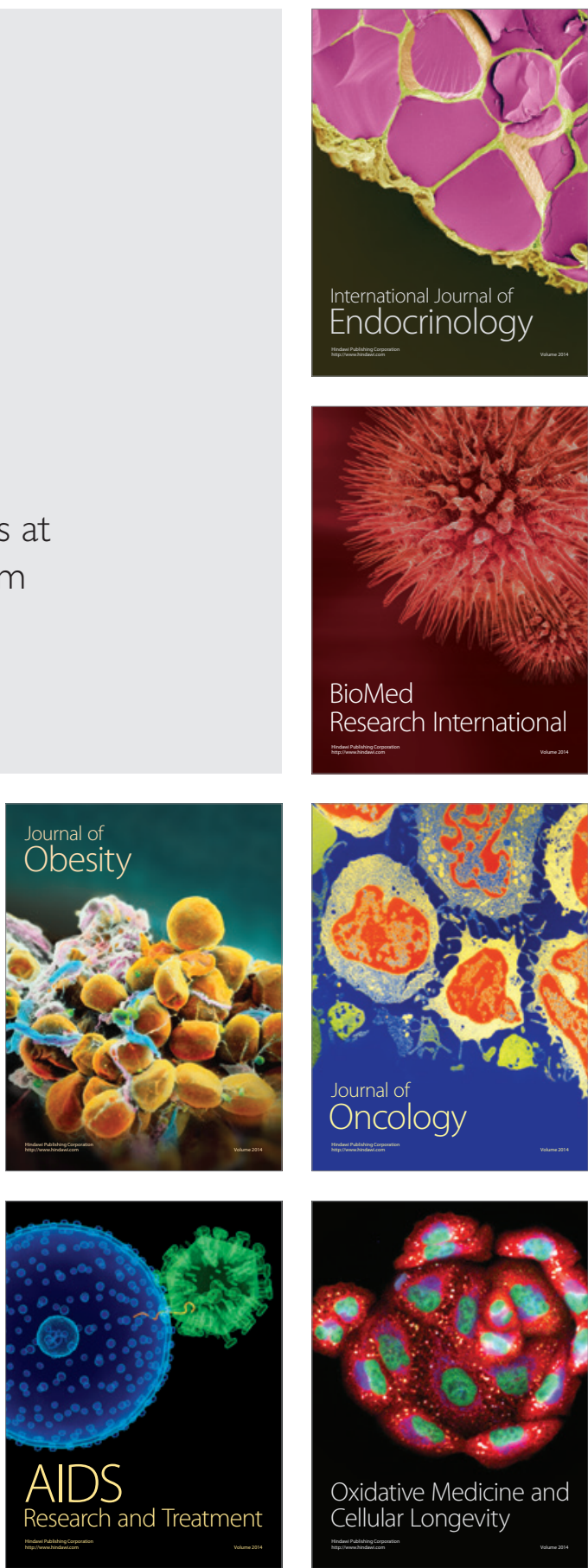